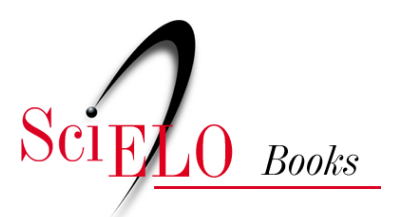

\title{
4. ¡Que viva el presidente Tales!
}

\author{
César Augusto Tapias Hernández
}

\section{SciELO Books / SciELO Livros / SciELO Libros}

TAPIAS HERNÁNDEZ, C.A. iQue viva el presidente Tales! In: Historias de familia: Etnografía delirante sobre el amor, la violencia y las drogas [online]. Bogotá: Editorial Universidad del Rosario, 2014, pp. 17-20. Textos de ciencias humanas collection. ISBN: 978-958-738-543-4. https://doi.org/10.7476/9789587385434.0005.

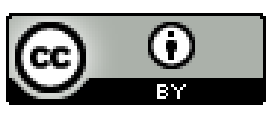

All the contents of this work, except where otherwise noted, is licensed under a Creative Commons Attribution 4.0 International license.

Todo o conteúdo deste trabalho, exceto quando houver ressalva, é publicado sob a licença Creative Commons Atribição $\underline{4.0}$.

Todo el contenido de esta obra, excepto donde se indique lo contrario, está bajo licencia de la licencia $\underline{\text { Creative }}$ Commons Reconocimento 4.0 . 


\title{
4. i Que viva el presidente Tales!
}

\author{
Algunas realidades necesitan ser hechas ficción \\ antes de ser captadas. \\ Veena Das, en Nicolás Espinosa, Política de vida y muerte
}

-En este país, en este momento con la cuestión de la paz hay muchas falencias, creo que debemos contribuir cada uno, para mejorar... Debemos mejorar para que la paz sea un poco más completa. Lo que pasa es que en este país hay gente que cree que un país sin pobres es un país bueno y están... Cómo te dijera, están en lo falso, porque en un país tiene que haber pobres para que el país sea... relativo.

Y Martha interviene aplaudiendo y agrega:

- Mejor dicho, a ese político de esposo mío no le falta sino el pregrado, el posgrado, la especialización, el doctorado y la corbata.

一Je, je, je, je, je... -ríe el auditorio.

De eso de la corbata, ya se encargaba Fred, mi primo mayor, quien encuentra una buscando en el armario del papito Fonso...

Se trata de mi tío Hétor Mario y de su ebriedad... Y también de la Martha. Pero... ¿qué problema hay con estar ebrios?, bien lo dijo ya Baudelaire, el poeta mayor: "Hay que estar siempre ebrio. Todo se reduce a eso, es la única cuestión. Para no sentir el horrible peso del tiempo, que os destroza los hombros doblegados hacia el suelo, debéis embriagaros sin cesar".

No es exagerado atribuirle a la ebriedad, a la del licor sobre todo, y también a la de las drogas, y la de los celos... un lugar destacado dentro de lo cotidiano de mi familia. Y, bueno, la verdad, más allá de cualquier familia en especial, un lugar destacado en la gran mayoría de muestra sociedad, para bien o para mal... El Hétor, sin que nadie le hubiera dado bomba, comenzó a dar su discurso ante la cámara de video con la que Rigo graba últimamente cualquier reunión de los Tales. Esa cámara 
cada vez resulta ser otro elemento bien incorporado en nuestra vida familiar. Así, pues, sin importar la bulla de otros ebrios... ebrias también las palabras, el Hétor desenfunda las suyas...

Y yo estaba tras la cámara, ahí pegado en un primer plano, no solo para recuperar bien el sonido: palabras embebidas, sino para ver de cerca los ojos de mí tío Hétor... su rostro...

Entonces lo recordé caminando por los pasillos del INEM, ebrio quizás en aquella época de fórmulas de química y recordé también sus inmensos deseos por ir a la universidad, ebrio tal vez en esos días de curiosidad. Tan ebrio finalmente como yo de aquel instante...

Suspendido

Lelo

Viendo por la cámara...

Tan ido... que hasta Rigoberto, el dueño de la cámara (y del archivo visual de esta casa) creía que debía dirigirme, porque esos planos míos... Humm... Y yo me dejaba, ebrio en el instante...pensé: “¡Saldrían planos borrachos! Ve, corre un poquito la cámara, no te arrimés tanto... Coge mejor a Martha”.

Y Martha dejaba ver sus sonrisas y parecía más bien que las regalaba. Seguramente se ha tomado la misma cantidad de tragos que Hétor... Juntos comparten esta fiesta... También comparten el amor, un par de hijos y muchas peleas. Él hablando, ella escuchando, él asumiéndose al discurso y ella dándole besos... Fred apareció con una corbata y ya en la sala eran muchos más los que querían ver aquello y lo disfrutaron mucho, pero ninguno como el mismo tío Hétor y su esposa transformada ya en una periodista, preguntando: “Qué le falta a la paz, señor presidente?

Y el tío con las gafas de Fred y la corbata del papito, sentado en la sala haciendo carrizo e incorporando a su discurso la puesta en escena de sus manos, así como los políticos de ahora que se hacen llamar gerentes... Era el presidente Tales apoderado de la escena, quien contestaba:

- Lo que le falta a la paz es un acogimiento de todos los seres humanos, que tengamos una conciencia de reconciliación, que pensemos por todos, porque la paz es una globalización donde cada uno tenemos que poner su granito de arena...

-Y ¿los desplazados, las víctimas de esta guerra?

-Yo creo que en la confrontación del país hay una falencia donde todos debemos aportar... Frente a los desplazados y los huérfanos, pues el país siempre se ha caracterizado por que las personas que más riqueza tienen siempre han vivido mejor que los que nada tienen... 
-Y Bush que no quiere a Colombia, ¿qué será del Plan Colombia?

- Bush al principio de su campaña siempre estimó apoyar el Plan Colombia, dónde están todas nuestras herramientas con las que vamos a trabajar todos...

— ¿Cuánto despeje espera darle a la guerrilla, todo el país, solamente la mitad, puede darles Cuba o Venezuela..?

-En estos momentos tenemos un problema con la gente de las FARC, ellos tienen un despeje hasta el 7 de diciembre, ellos se pronunciaron en esta semana y dijeron... muchas cosas...

Pero los asistentes, sobrinos, hermanos, la mamita, los espectadores del show, todos conservadores aunque liberados por el alcohol... lo abuchean: Buuuuuuuuuuuuuuuuuuuuuu

— ¿El 7 de diciembre? —alcanzó a decir uno en el público...

—No, este man no sabe dónde está parado — replicó otro— Ni cuándo está gobernando, sentenció uno más. Y la periodista le rescata de las garras de la "opinión pública”.

- ¿Hay que ser acaso como Fujimori?

—En estos momentos — continua el presidente, digo mi tío — este no es el mejor momento de Fujimori, porque su primera campaña se vio afectada por los aportes del narcotráfico, según lo publicó "El Osito", hermano de Pablo, en su último libro...

Y todo finalmente se hizo recocha. Pasamos de lo que bien podría ser el florecimiento del alma, desatadas las ataduras por el alcohol, a las inocentes risotadas de los que se pillaron aquella no tan extraña cosa: UN BORRACHO HABLANDO GÜEVONADAS. Y ¿qué con eso?, si hacía parte de la fiesta. Solo que esta vez fue un simulacro de un buen show nacional en vivo y en directo, con cámara incluida en caso de que resultasen interesados para una transmisión en diferido, con público y periodista a bordo, sobre todo la periodista... el presidente Tales ya medio enredado, hablando y hablando... Embriagados él y su esposa "para no ser esclavos martirizados del tiempo", cosa también dicha ya por Baudelaire... y tal y tal...

¿Que viva el presidente Tales!

Fulminante acusó la periodista y fin de la emisión.

$\infty \infty \infty$

Discurso, objeto, paradigma... Las teorías solo son instrumentos para indagar la "realidad", pero no son la realidad (Cajas, 2009); sin embargo, como coautor de 
la confección de estas viñetas, estoy tomando decisiones que no son neutras: ¿qué narrar y cómo narrarlo?, ¿qué esconder?, ¿qué cambiar?, ¿qué maquillar? Aparentemente no quiero interpretar. No quiero analizar. Solo describir. Espero me entiendan, pues como dice el dicho "es difícil hablar de la familia en público", pero como este libro le pertenece al lector, lo invito a intentar comprender el drama.

Si bien he planteado que este trabajo ha sido escrito en forma de montaje literario, a la manera del collage tussigniano, he procurado ir guardando el hilo de una experiencia etnográfica que busca abrir surcos o caminos a posibilidades de entendimiento que se abren desde la sociología para el estudio de fenómenos sociales. Lo que no se delimita claramente es la posibilidad de saber si los testimonios de este texto híbrido son textuales o se inclinan de alguna manera entre las delgadas líneas que van entre realidad y ficción. ¿Qué cree usted, amable lector? De ahí que sea una antropología que se enfoque en el desvarío de la alucinación, del enamoramiento, de una individualidad abrumada por la familia, institución autoritaria que le oprime y controla con la excusa de amarle, o ¿̇será al revés? ¿Que este experimento literario y antropológico me propone como el controlador sino de una experiencia, de su representación, y luego mis familiares me censurarán? Como Taussig, el antropólogo australiano vuelto jaguar en las selvas colombianas, creo que esta escritura trabada es un recurso contra el terror. ¡La familia es una maquinaria de terror! $\mathrm{Y}$ la escritura sobre ella es un recurso que me exige una forma otra de representación etnográfica... La evocación solo posible a la manera del discurso chamánico, de la poesía, del teatro, del surrealismo... Sí, esta etnografía es como una cura chamánica a la enfermedad social que conformamos, como una contra ante el terror de la vida diaria... Y contra la deconstrucción meramente académica que quiere explicar la vida de los salvajes (Reynoso, 2008). 